\title{
Sempervirine inhibits RNA polymerase I transcription independently from p53 in tumor cells
}

\author{
Cinzia Caggiano', Eugenia Guida (1)', Federica Todaro', Pamela Bielli', Mattia Mori², Francesca Ghirga ${ }^{3}$, \\ Deborah Quaglio ${ }^{4}$, Bruno Botta ${ }^{4}$, Fabiola Moretti $\mathbb{B}^{5}$, Paola Grimaldi ${ }^{1}$, Pellegrino Rossi ${ }^{1}$, Emmanuele A. Jannini ${ }^{6}$, \\ Marco Barchi (1) and Susanna Dolci ${ }^{1}$
}

\begin{abstract}
In the search of small molecules that can target MDM2/p53 pathway in testicular germ cell tumors (TGCTs), we identified sempervirine (2,3,4,13-tetrahydro-1 H-benz[g]indolo[2,3-a]quinolizin-6-ium), an alkaloid of Gelsemium sempervirens, that has been previously proposed as an inhibitor of MDM2 that targets p53-wildtype (wt) tumor cells. We found that sempervirine not only affects cell growth of $p 53$-wt cancer cells, but it is also active in $p 53$-mutated and p53null cells by triggering p53-dependent and independent pathways without affecting non-transformed cells. To understand which mechanism/s could be activated both in p53-wt and -null cells, we found that sempervirine induced nucleolar remodeling and nucleolar stress by reducing protein stability of RPA194, the catalytic subunit of RNA polymerase I, that led to rRNA synthesis inhibition and to MDM2 block. As shown for other cancer cell models, MDM2 inhibition by nucleolar stress downregulated E2F1 protein levels both in p53-wt and p53-null TGCT cells with the concomitant upregulation of unphosphorylated pRb. Finally, we show that sempervirine is able to enter the nucleus and accumulates within the nucleolus where it binds rRNA without causing DNA damage. Our results identify semperivirine as a novel rRNA synthesis inhibitor and indicate this drug as a non-genotoxic anticancer small molecule.
\end{abstract}

\section{Introduction}

Sempervirine $\quad(2,3,4,13$-tetrahydro- $1 H$-benz $[g]$ indolo[2,3- $a]$ quinolizin-6-ium) is an alkaloid compound found as a constituent of Gelsemium sempervirens (Loganiaceae), a greenleaved plant that is under medicinal as poisonous plants. Previous reports explored the role of sempervirine as an anticancer drug, showing dramatic effects on cancer cell growth both in vitro and in vivo ${ }^{1,2}$. Recently, in a biomolecular screening, sempervirine has been identified as a selective

\footnotetext{
Correspondence: Marco Barchi (marco.barchi@uniroma2.it) or

Susanna Dolci (dolci@uniroma2.it)

${ }^{1}$ Department of Biomedicine and Prevention, University of Rome Tor Vergata, Rome, Italy

${ }^{2}$ Department of Biotechnology, Chemistry and Pharmacy, University of Siena, Siena, Italy

Full list of author information is available at the end of the article

These authors contributed equally: Cinzia Caggiano, Eugenia Guida

Edited by Ana Janic
}

inhibitor of murine double minute 2 (MDM2) ubiquitin ligase activity and it has been evidenced a role in inducing apoptosis in $p 53-w t$ cancer cell lines ${ }^{3}$.

MDM2 is a RING finger E3 ubiquitin ligase that negatively regulates p53 levels by promoting its proteasomemediated degradation, thus inhibiting p53-mediated transactivation of target genes involved in DNA damage repair, cell cycle arrest, apoptosis, and senescence ${ }^{4}$. Among a myriad of upregulated genes, p53 induces the transcription of $M D M 2$ (or HMD2) itself, creating a negative feedback loop to limit the function of $\mathrm{p} 53^{5}$. $M D M 2$ can be overexpressed in tumors with $p 53-w t$ and it is overamplified in several histological types, such as sarcomas, glioblastomas, bladder carcinomas, cholangiocarcinomas, and testicular germ cell tumors (TGCT) ${ }^{6}$. The C-terminal of MDM2 can bind the C-terminal of the

\section{(c) The Author(s) 2020}

(c) (i) Open Access This article is licensed under a Creative Commons Attribution 4.0 International License, which permits use, sharing, adaptation, distribution and reproduction cc) in any medium or format, as long as you give appropriate credit to the original author(s) and the source, provide a link to the Creative Commons license, and indicate if changes were made. The images or other third party material in this article are included in the article's Creative Commons license, unless indicated otherwise in a credit line to the material. If material is not included in the article's Creative Commons license and your intended use is not permitted by statutory regulation or exceeds the permitted use, you will need to obtain permission directly from the copyright holder. To view a copy of this license, visit http://creativecommons.org/licenses/by/4.0/. 
highly related protein MDMX (HDMX or MDM4). Although MDMX does not have any E3 ligase activity, the MDM2-MDM4 heterodimer shows an optimal structure for E2-dependent p53 ubiquitination compared to MDM2 homodimers ${ }^{7}$.

Among solid neoplasias, TGCTs are the most frequent tumors that affect young men ${ }^{8}$. TGCT therapy is based on the stage and histology of the tumor and cisplatin, or platin derivatives are the first choice drugs, when chemotherapy is needed. Mortality from TGCT is due to tumor resistance to platin-based chemotherapy and the failure to clear all residual sites of disease after chemotherapy in the early treatment stages ${ }^{8}$. In vitro, cisplatin has been shown to be cytotoxic in human TGCT cell lines by inducing massive apoptosis ${ }^{9-11}$ and in response to platin chemotherapy a crucial role is played by $\mathrm{p} 53$, that following induction and posttranslational modifications activates the apoptotic pathway response $\mathrm{e}^{12}$.

TGCT are sensitive to cisplatin chemotherapy, however, a fraction of treated patients develops cisplatin resistance. Even if cisplatin has been shown to induce p53 response, in these tumors its resistance is not directly linked to p53 status, since it is rarely mutated or deleted. The frequency of amplification of MDM2 in TGCT, its mutually exclusive expression pattern with p53 mutations, and the ability to abrogate $w t$ p53 function make MDM2 an attractive target for the development of novel antitumor agents. One of MDM2-specific inhibitor is nutlin-3a (thereafter called nutlin) ${ }^{13}$ that has been shown to cooperate with DNA damage to induce apoptosis in TGCT cells ${ }^{14}$. In agreement with this notion, nutlin treatment enhances cisplatin toxicity in lung cancer, ovarian cancer, and sarcoma cell lines ${ }^{15,16}$. However, its poor bioavailability, high toxicity, and its limited effects on MDMX-overexpressing cells ${ }^{17}$ have made it a poor candidate to the clinic translation.

In an attempt to identify new small molecules that could target p53/MDM2 axis in TGCTs with better bioavailability, we tested sempervirine in in vitro assays. Unexpectedly, we found that the drug not only targeted $p 53-w t$, but also p53-mutated or p53-null tumor cell lines, while it was ineffective on non-transformed cells, and it significantly reduced cisplatin concentration in cytotoxic assays of resistant cells. Sempervirine not only increased p53 levels, as expected by its inhibitory activity on MDM2, but it also induced RPA194 (the catalytic subunit of RNA polymerase I (RNA Pol I)) degradation and nucleolar stress in p53-wt, p53-mutated, and p53-null TGCT cells. We found that RPA194 stability was dependent either on MDM2 levels or on its activity. Sempervirine preferentially bound to nucleolar rRNA without inducing DNA damage, supporting a role of sempervirine as ribosome biogenesis inhibiting agent. The ability of sempervirine to hit tumor, but not normal cells through RPA194 degradation, and its synergistic effect with cisplatin highlights its selectivity and versatility as an antitumoral agent.

\section{Results \\ Sempervirine induces cell cycle arrest and cell death in p53-wt and p53-null germ cell tumor lines}

Sempervirine (Fig. 1a) has been identified as a potent inhibitor of MDM2 E3 ligase activity on p53 in in vitro ubiquitylation assays, and as such it has been shown to activate the p53-mediated checkpoint and to inhibit cell growth in a p53-dependent manner. In the search of MDM2 E3 ligase inhibitors to block in vitro proliferation of TGCT cell lines, that are mostly $p 53-w t$, we subjected 2102EP(S), 2102EP(R), and NCCIT, three embryonal carcinoma TGCT cell lines, to a proliferation assay in the presence of increasing doses of sempervirine. 2102 $\mathrm{EP}(\mathrm{S})$ is a cisplatin-sensitive $p 53$-wt TGCT line ${ }^{18}$, while $2102 \mathrm{EP}(\mathrm{R})$ has been derived from 2102EP(S) following long-term cisplatin treatment, to induce cisplatin resistance ${ }^{19}$. Despite sempervirine was initially identified as effective only in $p 53-w t$ cell lines, we also included NCCIT cells, a naturally occurring $p 53-n u l l$ cell line, to test drug specificity. As control non-tumor cells, we used myometrial cells, adipose stromal cells (ASCs) and fibroblasts at early passages (p2-3). As shown in Fig. 1b and Supplementary Fig. 1c, cell survival similarly decreased in a dosedependent manner $72 \mathrm{~h}$ after sempervirine treatment for each tumor cell type, irrespective of cisplatin sensitivity or p53 status. On the contrary, we did not find any significant antiproliferative effect on myometrial cells nor fibroblasts. In parallel experiments, we also evaluated the effects of nutlin, an inhibitor of p53-MDM2 interaction, on TGCT cell survival. As shown in Supplementary Fig. 1a, we found 2102EP(S) more sensitive compared with the parental cisplatin-resistant cells, while NCCIT and myometrial cells were insensitive (Supplementary Fig. 1a, b). We also performed the colony formation assay of TGCT lines in the presence of sempervirine or nutlin to test the mean half-maximal inhibition of cell survival/proliferation $\left(\mathrm{IC}_{50}\right)$. As shown in Fig. 1c, colony formation was strongly inhibited by $1.6 \mu \mathrm{M}$ sempervirine in all three cell lines irrespective of $p 53$ status, while nutlin, as expected, was effective only in $p 53-w t$ cells. Furthermore, the $\mathrm{IC}_{50}$ of sempervirine was comparable between the cell lines, ranging from 0.46 to $0.67 \mu \mathrm{M}$, while the IC50 of nutlin was 1.7-fold and 10-fold higher in $2102 \mathrm{EP}(\mathrm{R})$ and in NCCIT, respectively, compared to 2102EP(S) (Fig. 1d).

To further confirm the sensitivity of TGCT cells to sempervirine, we expanded the proliferation assay to other $p 53-w t$ cell lines (GCT27(S) and (R), NT2D1(S), and (R), $218 \mathrm{~A}, 27 \mathrm{X} 1$ ), one additional p53-mutated cell line $\left(228 \mathrm{~A}^{20}\right.$, and a $p 53$-silenced $2102 \mathrm{EP}(\mathrm{S})$ cell line (sh-p53 $\mathrm{EP}(\mathrm{S})$ ). As additional control for $p 53$-mediated sensitivity, 
A<smiles></smiles>

$\mathrm{C}$
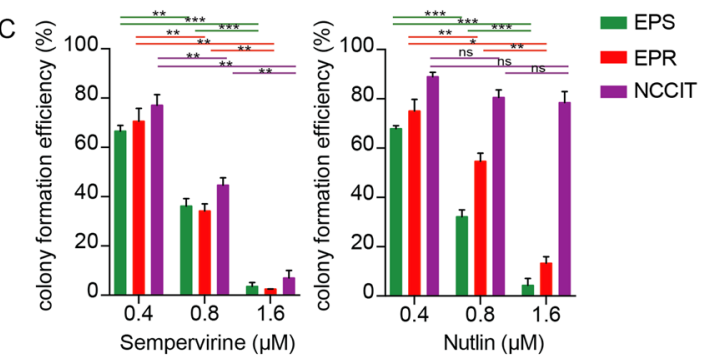

$E$

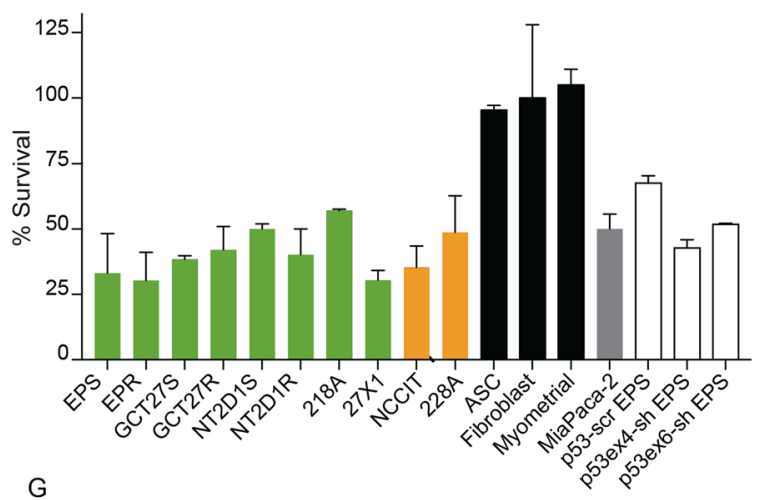

G
B

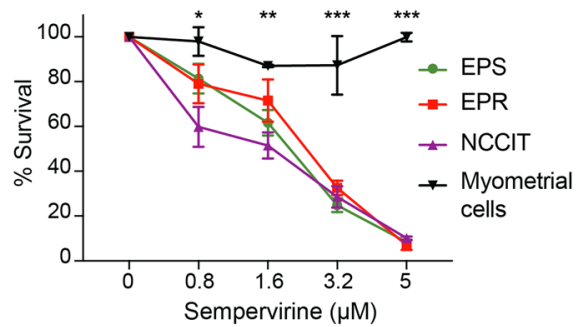

D

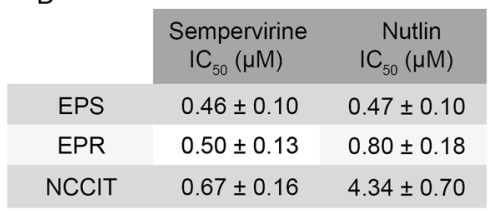

$\mathrm{F}$

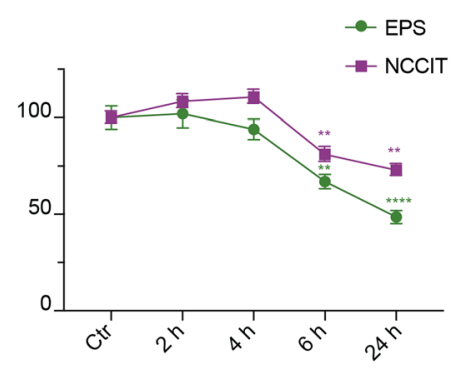

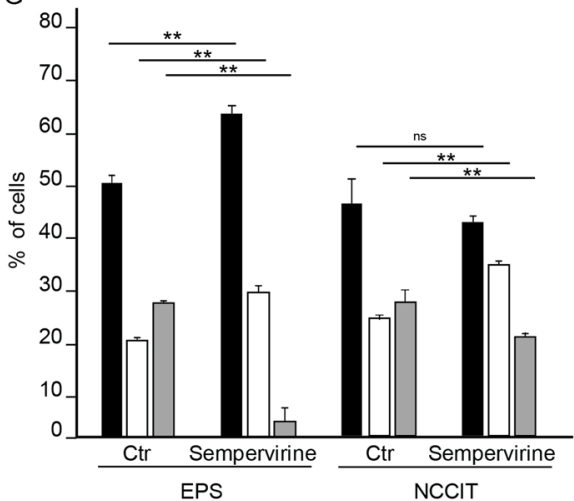

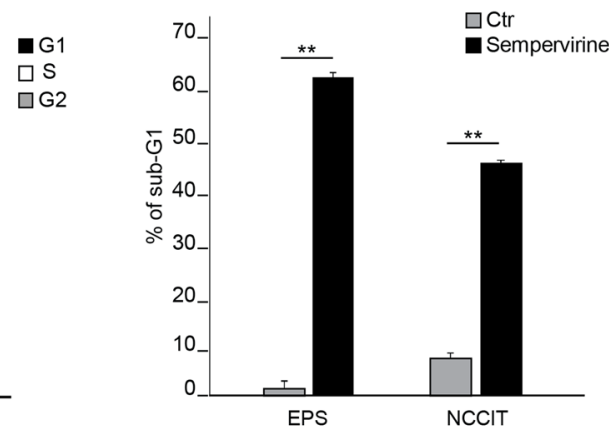

Fig. 1 Sempervirine induces cell death in p53-wt and p53-null germ cell tumor lines. A Chemical structure of sempervirine chloride. B Mean half-maximal inhibition of cell survival/proliferation $\left(\mathrm{IC}_{50}\right)$ of sempervirine after $72 \mathrm{~h}$ of culture in $2102 \mathrm{EP}(\mathrm{S})$ (EPS), 2102EP(R) (EPR), NCCIT, and myometral cells. ${ }^{*} p<0.05,{ }^{* *} p<0.01,{ }^{* * *} p<0.001$, unpaired $t$ test, number of biological replicates $(n) n=5$. C Colony formation assay on $2102 E P(S)$ (EPS), $2102 E P(R)(E P R)$, and NCCIT after treatment with $0.4,0.8$, and $1.6 \mu \mathrm{M}$ of sempervirine and nutlin, respectively. ${ }^{* * * *} p<0.0001,{ }^{* * *} p=0.0006$. Twoway ANOVA, Tukey's multiple comparisons test, $n=3$. D IC $\mathrm{C}_{50}$ of sempervirine and nutlin treatment in 2102EP(S) (EPS), 2102EP(R) (EPR), and NCCIT. E Proliferation assay on several TGCT cell lines p53-wt (green) and p53-mut or -null (yellow), MiaPaCa-2 (gray), control cell lines (black), and silenced $2102 \mathrm{EP}(\mathrm{S})$ (white) treated with $5 \mu \mathrm{M}$ sempervirine for $24 \mathrm{~h}$. Mean $\pm \mathrm{SD}, n=3$. F Reversibility after $2,4,6$, or $24 \mathrm{~h}$ of treatment with $5 \mu \mathrm{M}$ sempervirine. ${ }^{* *} p<0.01,{ }^{* * *} p<0.0001$, paired $t$ test, $n=3$. G FACS analysis of sempervirine-treated 2102EP(S), and NCCIT cells showing the percentage of cells in G1, S, G2 cell cycle phases (left) and the percentage of sub-G1 cells (right) after $72 \mathrm{~h}$ of treatment. ${ }^{*} p<0.05,{ }^{*} p<0.01$, unpaired $t$ test, $n=3$. 
we included a pancreatic adenocarcinoma cell line (Mia$\mathrm{PaCa}-2)$ that carries the $\mathrm{R} 248 \mathrm{~W}$ mutation in $\mathrm{p} 53$. We observed that all the TGCT and pancreatic cell lines showed similar sensitivity to sempervirine at $5 \mu \mathrm{M}$ concentration, regardless of the $p 53$ status and tumor type (Fig. 1e).

We then tested reversibility of sempervirine treatment by assessing cell survival after drug withdrawal at different time points. As shown in Fig. 1f, withdrawal of sempervirine $4 \mathrm{~h}$ after its addition did not induce significant cell death effects within the next $24 \mathrm{~h}$ of culture both in $p 53$ $w t$ and -null cells, while extending to $6 \mathrm{~h}$ of treatment $>30 \%$ of $2102 \mathrm{EP}(\mathrm{S})$ and $20 \%$ NCCIT cells underwent cell death.

FACS analysis showed that the percentage of cells in G1 phase was increased at the expenses of G2 phase in sempervirine-treated $2102 \mathrm{EP}(\mathrm{S})$ cells after $72 \mathrm{~h}$, while NCCIT were arrested in $\mathrm{S}$ phase, as expected for $p 53$ deficiency. Accordingly, the sub-G1 fraction of sempervirine-treated cells strongly increased for both cell types, although 2102EP(S) cells showed maximal response to sempervirine (Fig. 1g).

\section{Sempervirine and cisplatin synergize to suppress TGCT cell} growth, and to induce p53 and MDM2 accumulation

To understand if treatment of TGCT cells with sempervirine might be functional to increase their response to cisplatin, we compared the survival of cell lines treated with cisplatin monotherapy and combined therapy with sempervirine. By a dose-response analysis, we calculated that the $\mathrm{IC}_{50}$ dose for cisplatin in $2102 \mathrm{EP}(\mathrm{S})$ and NCCIT cells was $\sim 3.3 \mu \mathrm{M}$, while at this drug concentration $>70 \%$ of $2102 \mathrm{EP}(\mathrm{R})$ were still viable (Fig. 2a). Next, we treated either cisplatin-sensitive or resistant cells with scalar doses of both drugs for $72 \mathrm{~h}$. Cisplatin sensitivity threshold $(3.3 \mu \mathrm{M})$ was restored in $2102 \mathrm{EP}(\mathrm{R})$ cells when sempervirine was administered at $1.6 \mu \mathrm{M}$ concentration, while it was lowered to $1.5 \mu \mathrm{M}$ in 2012EP(S) and NCC1T cells (Fig. 2a). Similar results were obtained using cisplatin in combination with $1.6 \mu \mathrm{M}$ nutlin (Supplementary Fig. 1d, e), although not effective in the p53-null NCCIT cell line (Supplementary Fig. 1f). As anticipated by its inhibitory effect on MDM2 ubiquitin ligase activity, sempervirine strongly increased p53 and p53Ser 15 phosphorylation levels, and this effect was more evident compared to nutlin or to the DNA-damaging effect of cisplatin in $p 53-w t$ TGCT cells (Fig. $2 \mathrm{~b}$ ). Parallel to the increase of p53 levels, also MDM2 levels were upregulated by sempervirine in p53-wt cells. As expected, MDM2 levels were basally low in p53-null cells, consistent with the transcriptional role of p53 on MDM2 expression (Fig. $2 b)$.

While nutlin was active only on $p 53-w t$ cells, sempervirine induced an increase of apoptosis and cPARP levels in all the three TGCT lines (Fig. 2b), that was more evident in $2102 \mathrm{EP}(\mathrm{S})$ line. Similarly to nutlin, we found that sempervirine significantly upregulated $p 53$ target gene expression, as shown by the increased levels of p21, BAX, DRAM, PUMA, GADD45, and TIGAR, but not of RAD51, in cisplatin-sensitive cells and to a minor extent in cisplatin-resistant $p 53$ - wt cells, while none of the genes were upregulated in p53-null cells (Supplementary Fig. 2a). To understand if the two other members of p53 family, p63 and p73, might mediate the cytotxic effects of sempervirine also on p53-null cells, we monitored their protein levels either in both the cell lines; however, we did not find any significant effect (Supplementary Fig. 2b). Sempervirine cytotoxicity was not mediated by DNA damage, since we did not find any increase of $\gamma \mathrm{H} 2 \mathrm{AX}$ foci, as revealed by immunofluorescence analysis (Supplementary Fig. 2c). Overall these data indicate that sempervirine can induce cell death by activating p53dependent and independent pathways.

\section{Sempervirine treatment induces nucleolar stress in p53-wt and -null cells}

Tumor cell lines are characterized by the presence of large and prominent nucleoli. By light microscopy, we noticed that the nucleolar compartments of either $p 53-w t$ or p53-null cell lines were almost completely disassembled after $24 \mathrm{~h}$ of sempervirine, but not after nutlin treatment (Fig. 3a). By immunofluorescence analysis, we found that nucleolin labeling redistributed from the granular component and dense fibrillar center of the nucleoli to the nucleus following $6 \mathrm{~h}$ of sempervirine treatment both in $2102 \mathrm{EP}(\mathrm{S})$ and NCCIT cells, and its levels were strongly decreased after $24 \mathrm{~h}$ of sempervirine treatment, as confirmed by western blot analysis (Fig. 3b, c). Also pancreatic cancer MiaPaCa-2 cells, that carry a mutated $p 53$ allele, showed a similar pattern of nucleolin staining, indicating that sempervirine-induced nucleolar stress independently from their p53 status (Supplementary Fig. 3). As a control, we included human myometrial cells, that are insensitive to sempervirine (Fig. 1b) and did not show redistribution nor decrease of nucleolin levels (Fig. 3b). To understand if nucleolar stress could be a common mechanism for sempervirine to induce p53dependent or independent cell death, we assessed if the drug might affect other nucleolar protein components. Indeed, we found that RPA194, the catalytic subunit of RNA Pol I, but not upstream binding-factor-1 (UBF-1) protein levels (Fig. 3c, d), were strongly downregulated following $24 \mathrm{~h}$ of treatment either in $p 53-w t$ or -null cells. To understand if sempervirine was affecting posttranscriptional regulation of RPA194, we also evaluated its mRNA levels and found that either RPA194 or UBF or TTF1, a factor involved in termination of rRNA transcription, were not affected (Fig. 4a). In support to these 


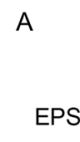

A A
EPS

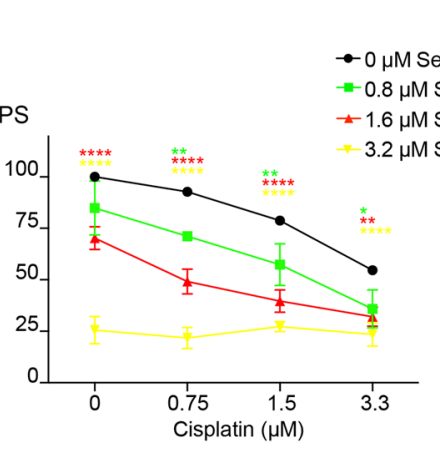

EPR

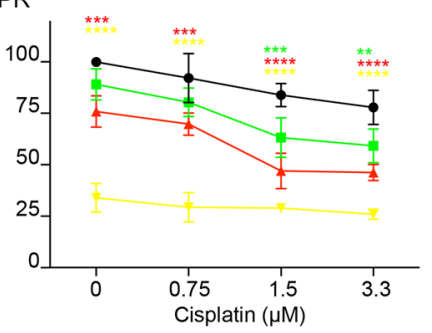

NCCIT

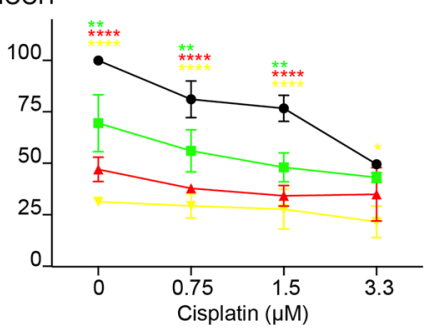

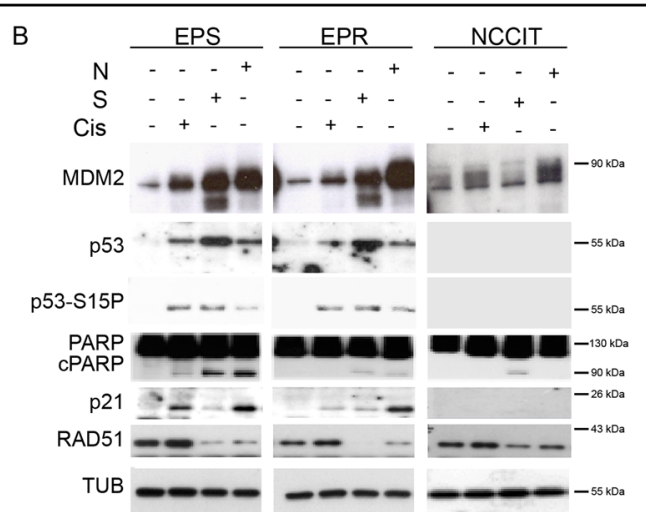

Fig. 2 Combination of sempervirine and cisplatin affects TGCT cell growth and induces p53 and MDM2 accumulation. A 2102EP(S) (EPS), 2102EP(R) (EPR), and NCCIT sensitivity to different doses of cisplatin in combination with different doses of Sempervirine. ${ }^{*} p<0.05,{ }^{* *} p<0.01,{ }^{* * *} p<$ $0.001,{ }^{* * * *} p<0.0001$, Two-way ANOVA, Dunnett's multiple comparisons test, $n=3$. B Western blot analysis of 2102EP(S) (EPS), 2102EPR (EPR), and NCCIT cell line extracts after $24 \mathrm{~h}$ of treatment with sempervirine, cisplatin, or nutlin, for MDM2, p53, and p53-S15P, PARP, CPARP, p21, and RAD51. Tubulin is the reference gene; $n=3$.

results, we found that total and phosphorylated protein levels for the catalytic subunit of RNA Pol II (RPB1), as well as its mRNA, were not affected, indicating that sempervirine does not inhibit mRNA transcription (Figs. $3 \mathrm{~d}$ and $4 \mathrm{a})$.

We found that the reduction of RPA194 was appreciable starting from $6 \mathrm{~h}$ of sempervirine treatment both in p53-wt and p53-null cells, and corresponded to the time point in which such treatment became irreversible (Figs. If and 3c). The decrease of RPA194 levels after 6 or $24 \mathrm{~h}$ of sempervirine treatment was partially reversed by the concomitant treatment with proteasome inhibitor MG132 added in the last $6 \mathrm{~h}$ of culture (Fig. 3e, f), while nutlin was not effective (Fig. 3f). Moreover, nutlin did not modify RPA194 levels (Fig. 3f), further confirming that the two drugs blocked MDM2 through different mechanisms of action. These results suggest that sempervirine activated rapid proteasome-mediated degradation of RPA194, inducing ribosomal stress.
To assess if MDM2 expression was also required to protect RPA194 stability, we transiently silenced MDM2 in either $p 53-w t, p 53$ stably silenced cells ( $p 53-s c r \mathrm{EP}(\mathrm{S})$, or $p 53$ ex4-sh EP(S)) or NCCIT cells (p53-null), with scr or MDM2 siRNAs. We found that RPA194 levels were reduced by MDM2 silencing in all the cell lines irrespective of p53 status, and sempervirine addition further reduced RPA194 levels (Fig. 3g). These results suggest that MDM2 protects RPA194 stability.

\section{Sempervirine represses rRNA synthesis}

We then monitored if sempervirine was affecting rRNA synthesis rate as reflected by the levels of short-lived $5^{\prime}$ and $3^{\prime}$ external transcribed spacer (5'ETS and $3^{\prime}$ ETS, respectively) rRNAs of the $47 \mathrm{~S}$ pre-rRNA. Primer sets were designed in the $18 \mathrm{~S}$ processed regions within the $47 \mathrm{~S}$ precursor RNA that undergo more rapid processing during rRNA synthesis. When testing $p 53-w t$ cells, we found a reduction of the $5^{\prime}$ ETS and $3^{\prime}$ ETS levels after $6 \mathrm{~h}$ 


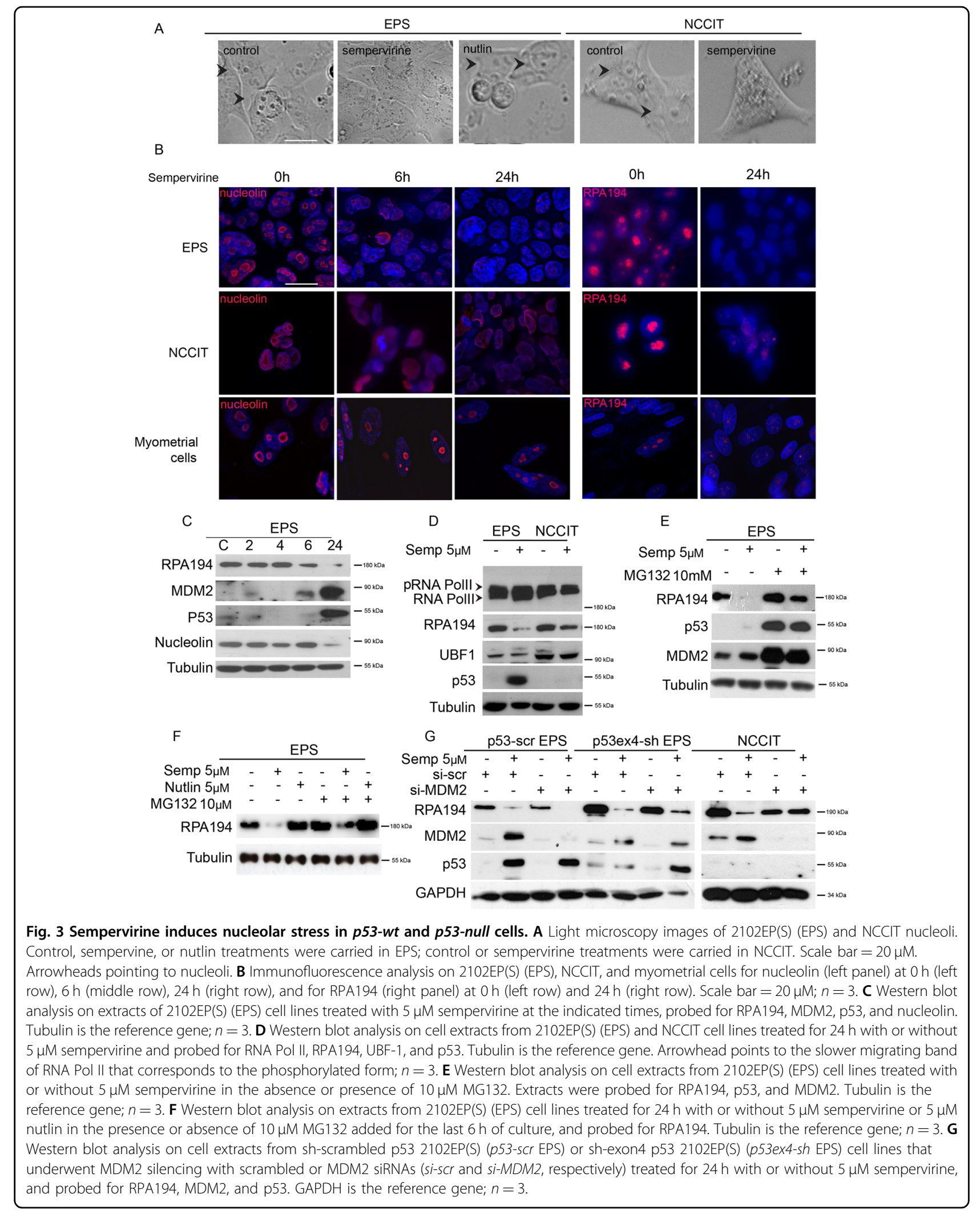




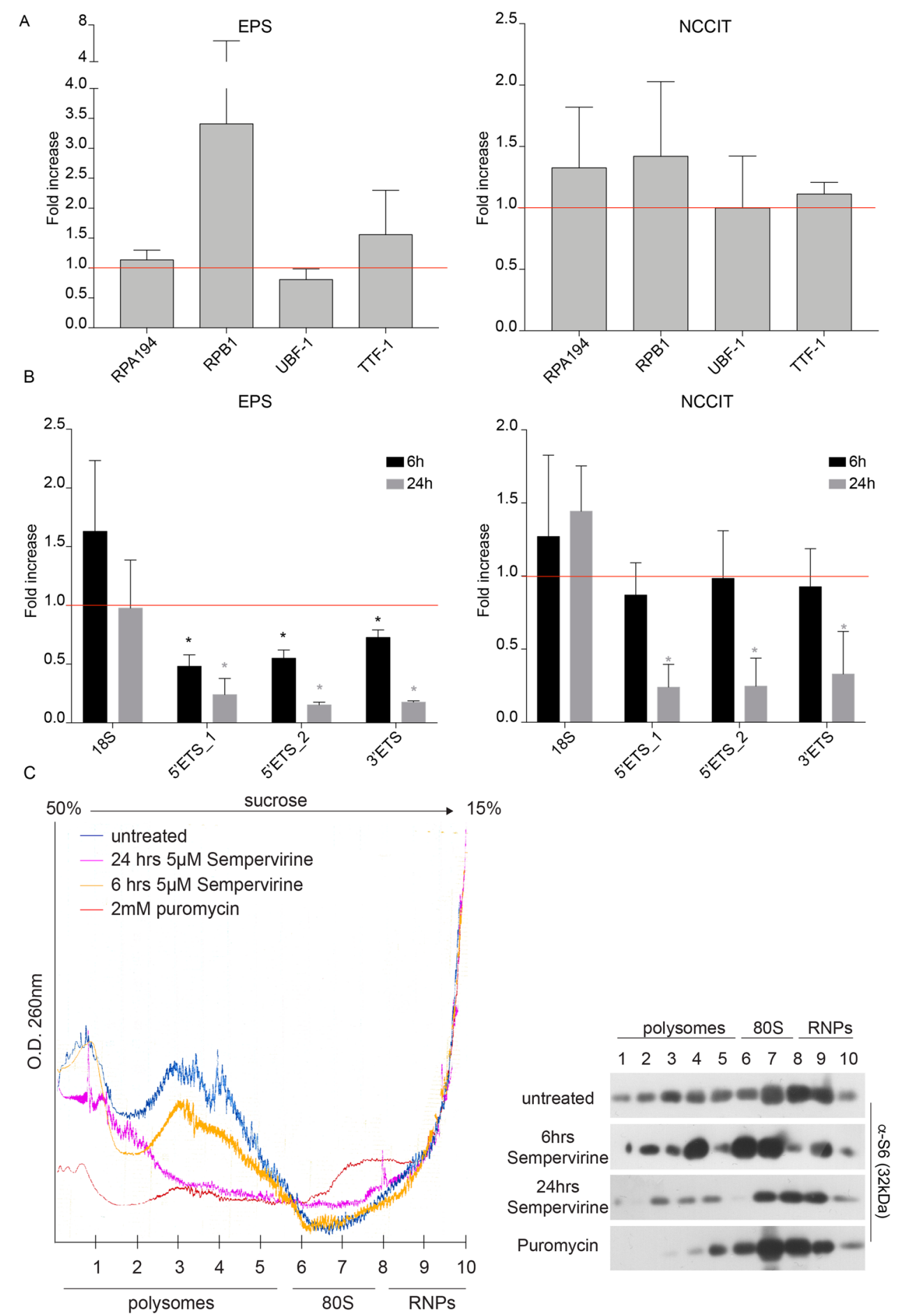

Fig. 4 Sempervirine represses rRNA synthesis and ribosome assembly. A RT-qPCR for RPA194, RBP1, UBF-1, and TTF1 mRNAs from 2102EP(S) (EPS) or NCCIT treated for $24 \mathrm{~h}$ in the presence or absence of $5 \mu \mathrm{M}$ sempervirine. Fold change is shown relative to the control (untreated 2102EP(S) (EPS) or NCCIT, represented by the red line, HPRT was used as reference gene). Mean \pm SD, $n=3$. B qRT-PCR for 18 S, 47S-specific 5'ETS (5'ETS_1), 18 S $5^{\prime}$ junction (5'ETS_2), $18 \mathrm{~S} 3^{\prime}$ junction (3'ETS) RNAs from 2102EP(S) (EPS), or NCCIT treated for 6 or $24 \mathrm{~h}$ with $5 \mu \mathrm{M}$ sempervirine. Fold change is shown relative to the control (untreated $2102 \mathrm{EP}(\mathrm{S})(\mathrm{EPS})$ or NCCIT, represented by the red line, HPRT was used as reference gene). Mean $\pm \mathrm{SD}, n=3 .{ }^{*} p<$ 0.05 , paired $t$ test. C Polysomes fractionation profiling of 2102EP(S) cells at 6 and $24 \mathrm{~h}$ after treatment with $5 \mu \mathrm{M}$ sempervirine, or after 15 min with $2 \mathrm{mM}$ puromycin (left panel) and western blot analysis of the relative fractions probed for 56 (right panel); $n=5$. 

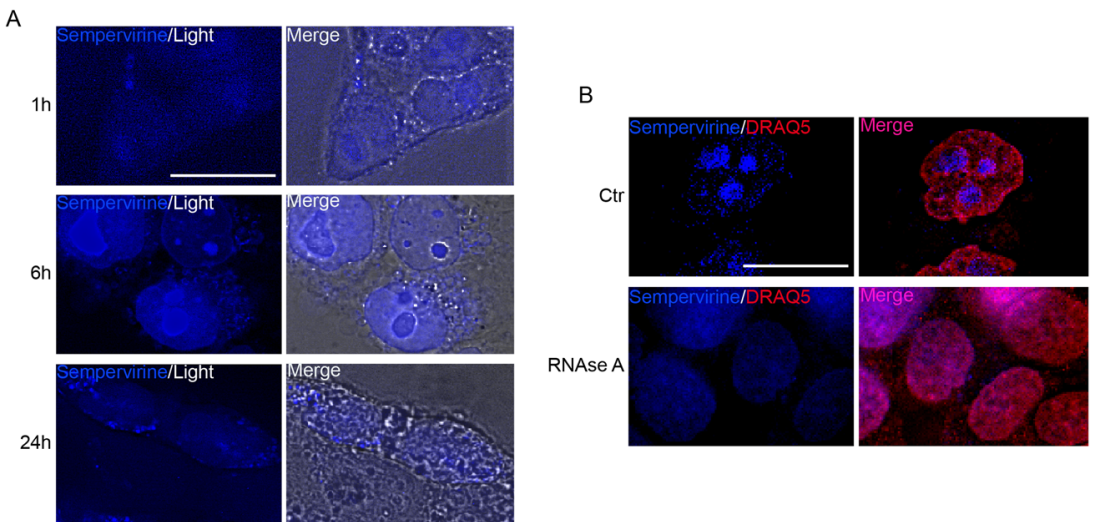

Fig. 5 Sempervirine is a fluorescent molecule and preferentially binds to rRNA. A Fluorescence and light microscopy images of in vivo labeled NCCIT cells after 1, 6, and $24 \mathrm{~h}$ of incubation with $5 \mu \mathrm{M}$ sempervirine. Scale bar $=20 \mu \mathrm{M}$. $n=3,60$ inspected fields. B Fluorescence images of fixed/ permeabilized control NCCIT cells treated with or without $100 \mu \mathrm{g} / \mathrm{ml}$ RNAseA (15 min), and stained with sempervirine and Draq5 as nuclear counterstain. Scale bar $=20 \mu$ M. $n=2,40$ inspected fields.

of sempervirine treatment that was further decreased after $24 \mathrm{~h}$, while the levels of $18 \mathrm{~S}$ subunit did not change. In p53-null cells, we found that $5^{\prime}$ and $3^{\prime}$ ETS levels decreased only after $24 \mathrm{~h}$ of sempervirine treatment but not after $6 \mathrm{~h}$, suggesting that RPA194 activity was more stable in $p 53$ null cells (Fig. 4b). Altogether these results suggest that sempervirine induces instability of the $47 \mathrm{~S}$ precursor levels that is in line with the reduction of RPA194 protein.

Although $18 \mathrm{~S}$ RNA levels were not affected, we investigated if the translational apparatus might be influenced by sempervirine treatment. To this end, we performed ribosome profiling experiments in $2102 \mathrm{EP}(\mathrm{S})$ cells treated for 6 or $24 \mathrm{~h}$ with the drug. As shown in Fig. 4c, a slight decrease of the lighter polysome fractions was observed after $6 \mathrm{~h}$ of sempervirine, while the distribution of heavier fractions was almost comparable. An altered ribosomal profile was found after $24 \mathrm{~h}$ of sempervirine treatment, and the abundance of ribosomes engaged in polysomes was strongly reduced compared to control profiles (Fig. 4c). Moreover, we did not find any increase of the monosome fraction, while puromycin treatment, through premature chain termination, disassembled heavy polysomes fractions but not monosomes (Fig. 4c), suggesting that sempervirine induced ribosomal disaggregation. Similar results were obtained also in p53-null cells (NCCIT and p53ex4-sh EP(S), data not shown).

\section{Sempervirine binds rRNA}

BMH-21 and amodiaquine, two molecules that affect RNA Pol I stability, have been shown to intercalate DNA and affect RNA Pol I binding to rDNA ${ }^{21,22}$. Sempervirine is a fluorescent compound that binds both DNA and RNA with lower affinity compared to ethidium bromide, and shows a maximum emission at $440 \mathrm{~nm}$ wavenlength when excited in the ultraviolet spectrum ${ }^{23}$. Thus, using NCCIT as model cells, that show larger nucleoli compared to 2102EP cells, we asked whether sempervirine stains nuclei and nucleoli evenly. To this end, we treated NCCIT cells with $5 \mu \mathrm{M}$ of the drug and then observed if nuclear labeling was occurring in vivo by fluorescence microscopy. Unexpectedly, we found that while cell nucleoplasm was faintly positive, nucleoli were brightly stained, suggesting that sempervirine was preferably binding to rRNA. The intensity of nucleolar labeling increased over time, being barely appreciable after $1 \mathrm{~h}$ and peaking at $6 \mathrm{~h}$ of incubation, the time point of irreversibility of sempervirine cytotoxic effect, while following $24 \mathrm{~h}$ of culture nucleolar fluorescence disappeared due to nucleolar disassembly (Fig. 5a). To confirm that sempervirine was predominantly bound to nucleolar RNA, we treated fixedpermeabilized NCCIT cells with $100 \mu \mathrm{g} / \mathrm{ml}$ RNAse A for $15 \mathrm{~min}$, to degrade single-strand RNA. DNA was counterstained using Draq5, a dye that specifically stains double-stranded DNA. As shown in Fig. 5b, while control fixed cells showed brilliant nucleoli labeled by sempervirine, nucleolar staining was completely abolished in RNAse-treated cells, confirming that sempervirine associated to rRNA within nucleoli.

\section{E2F1/pRB pathway is involved in sempervirine-induced nucleolar stress}

Nucleolar stress cascade leads to the release of ribosomal proteins that sequester and inhibit MDM2, thereby increasing p53 stability ${ }^{24}$. Since we found that also $p 53-$ null cells underwent cell cycle arrest and nucleolar stress, we investigated which mechanism/s behind sempervirine might be acting in this setting. We reasoned that a potential candidate might be the E2F1/pRB pathway, that links ribosome biogenesis to cell cycle ${ }^{25,26}$. We found that E2F1 levels were decreased following sempervirine 
treatment both in p53-wt and p53-null cells, while the unphosphorylated form of $\mathrm{pRb}$ increased in both cell types (Fig. 6a, b). Although a similar effect on E2F1 with nutlin treatment was observed also in p53-null cells, in these latter, we did not find any increase of unphosphorylated pRb levels (Fig. 6a).

\section{Discussion}

To reinforce tumor-suppressor functions of p53, much effort has been devoted in the recent years to the development of molecules that uncouple it from MDM2 control. Among these, nutlins have been developed that prevent MDM2 binding to $\mathrm{p} 53$ in the p53-binding pocket, leading to p53 accumulation, cell cycle arrest, and apoptosis in $p 53-w t$ cancer cells ${ }^{13}$. The hematologic toxicity and the poor bioavailability of nutlins have made this class of drugs of difficult employment in the treatment of cancer, and new molecules are being developed to overcome this issue. By modulating the E3 ubiquitin ligase activity of MDM2, other small molecules have been isolated that block MDM2 autoubiquitylation, leading to increased p53 stability ${ }^{27}$. Sempervirine has been previously identified as an MDM2 E3 ligase inhibitor that stabilizes p53 and induces cell death in U2OS cells ${ }^{3}$; however, reports on its efficacy in killing cancer cells are scant and not well described ${ }^{1}$. We first investigated if sempervirine could inhibit cancer cell proliferation by targeting MDM2/p53 axis, paralleling its effects with those of nutlin on TGCT cell lines. While the drug inhibited cell growth in a wide panel of p53-wt TGCT cells, we found that, differently from nutlin, sempervirine also arrested p53-null TGCT and p53-mutated cancer cells. Interestingly, we found that the drug sensitized both p53-wt and p53-null cells to cisplatin treatment, restoring to $3.3 \mu \mathrm{M}$ the concentration needed to reach cisplatin $\mathrm{IC}_{50}$ in resistant cells, and reducing it to $1.5 \mu \mathrm{M}$ in $p 53-w t$ and $p 53-n u l l$-sensitive cells. We found that similarly to nutlin, sempervirine induced a consistent increase of p53 and MDM2 levels and of p53-inducible cell death genes in p53-wt cells. MDM2 is not only a transcriptional target of $\mathrm{p} 53$, but its protein levels can be also regulated by autoubiquitylation. Since we observed an increase of MDM2 also in p53-null cells, this suggested that the inhibition of MDM2-ubiquitylating activity by sempervirine triggered $\mathrm{p} 53$-independent mechanism/s of cell death. Apart from p53 degradation, that is the bestcharacterized function, MDM2 plays also a role in the control of p63 and p73 stability ${ }^{28-30}$, as well as of cell cycle-related proteins, such as myc, $\mathrm{p} 21^{31}$, or $\mathrm{E} 2 \mathrm{~F}^{32}$. In the search for a common mechanism of action, we evaluated if these players might be modulated by sempervirine treatment. We did not find any effect on the expression levels of the other members of p53 superfamily nor of myc (data not shown) and we excluded that, at the concentration used in our experiments, sempervirine induced DNA damage as revealed by the lack of $\gamma \mathrm{H} 2 \mathrm{AX}$ histone foci. The lack of $\mathrm{p} 21$ induction in p53-null cells by sempervirine treatment also ruled out the possibility that MDM2 inhibition enhanced p21 stabilization leading to cell cycle arrest, at least for p53-null cells.

Several studies have shown that MDM2 protects E2F1 from $\mathrm{SCF}^{\mathrm{SKP} 2}$ ubiquitylation and degradation through p53-independent mechanisms ${ }^{33,34}$. Moreover, MDM2 silencing or inhibition by ribosomal stress both downregulate E2F1 levels in p53-null cells, leading to cell cycle arrest ${ }^{34}$. Ribosome-associated proteins (RP) RPL5, RPL11, and RPL23, released during ribosomal stress, all bind the central domain of MDM2 and apart from inhibiting p53 ubiquitylation, they prevent MDM2 ability to protect E2F1 degradation inducing cell cycle arrest and cell death ${ }^{24,35-38}$. Thus, RP release during ribosomal stress can activate cell cycle arrest via p53-dependent or p53independent mechanisms ${ }^{26}$. RNA Pol I silencing has been shown to induce ribosomal stress that leads to cell cycle arrest through downregulation of E2F1 in the presence of increased levels of unphosphorylated $\mathrm{pRb}$. Since we found that sempervirine treatment downregulated E2F1 levels both in p53-wt and p53-null cells with the concomitant upregulation of the unphosphorylated form of $\mathrm{pRb}$, we hypothesized that apoptosis and cell cycle arrest induced by the drug might be linked to ribosomal stress. It is interesting to note that $\mathrm{pRb}$ has been shown to inhibit $\mathrm{Pol}$ I transcription by interacting with $\mathrm{UBF}^{39}$, and/or binding to the rDNA promoter ${ }^{40}$. Indeed, sempervirine induced nucleolar disruption and, most importantly, it promoted the degradation of RPA194, but not of UBF, nor of RNA Pol II catalytic subunit, suggesting that sempervirine interfered with rRNA but not mRNA transcription. The decrease of RPA194 protein levels was evident after $6 \mathrm{~h}$ of sempervirine treatment, a time point at which, when removed from culture, its cytotoxic effects were considered irreversible, even if proteasome inhibition could partially rescue RPA194 degradation. Sempervirine has been referenced as an MDM2 inhibitor on the basis of chemioluminescent methods that only reported the amount of autoubiquitylation and p53 ubiquitylation as a readout of MDM2 inhibition ${ }^{3}$. In our experiments, we observed that sempervirine affected RNA Pol I stability by increasing RPA194 sensitivity to proteasome degradation. This event led to the reduction of precursor-specific regions of $47 \mathrm{~S}$ rRNA that occurred more rapidly in $p 53-$ $w t$ compared to p53-null cells, indicating that sempervirine was affecting ribosome biogenesis. As a result, polysome profiling showed a slight decrease of the heavy complexes following $6 \mathrm{~h}$ of sempervirine that completely disappeared after $24 \mathrm{~h}$ of treatment strongly supporting ribosomal stress, as the cause of MDM2 inhibition and cell death via p53-dependent and independent pathways. 


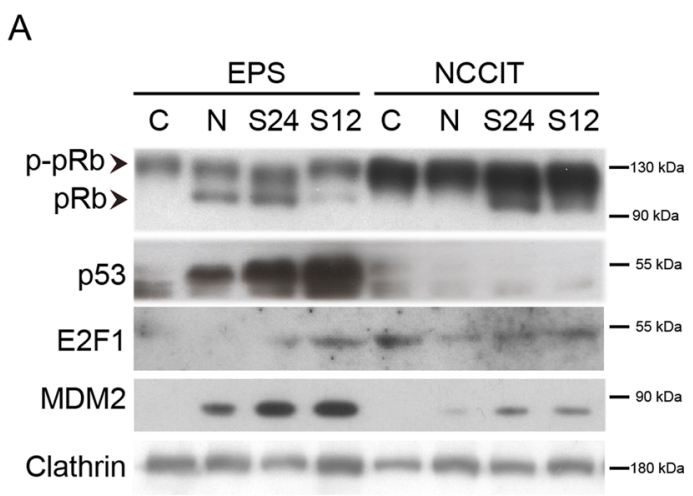

B

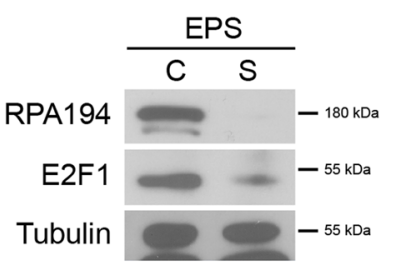

C

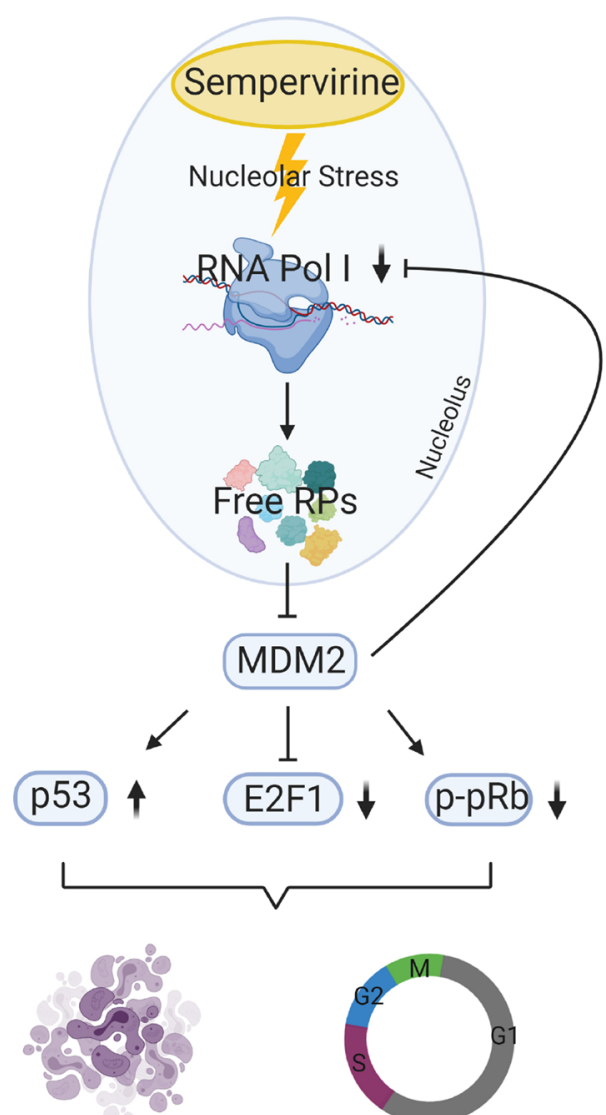

Apoptosis $\uparrow$

Cell Cycle $\downarrow$

Fig. 6 MDM2 inhibition causes E2F1 protein downregulation and pRb increase in $p 53-w t$ and $p 53-n u l l$ cells. A Western blot analysis on cell extracts from 2102EP(S) (EPS) and NCCIT cell lines treated for 12 and $24 \mathrm{~h}$ with or without $5 \mu \mathrm{M}$ sempervirine or $5 \mu \mathrm{M}$ nutlin probed for pRB, E2F1, p53, and MDM2. Clathrin is the reference gene. Arrowheads point to the two bands that correspond to a faster migrating band (unphosphorylated form, pRB) and a slower migrating band (phosphorylated form, p-pRB) of p130 retinoblastoma; $n=3$. B Western blot analysis on cell extracts from $2102 E P$ (S) (EPS) cells treated for $24 \mathrm{~h}$ with or without $5 \mu \mathrm{M}$ sempervirine, and probed for E2F1. Tubulin is the reference gene; $n=3$. C Schematic representation of sempervirine mechanisms of action: sempervirine binds to nucleolar RNA and affects RPA194 stability, leading to nucleolar stress and MDM2 inhibition. Arrows indicate the concomitant activation of cell death and cell cycle arrest pathways. 
To date, few drugs have been demonstrated to induce RPA194 degradation, in particular BMH-21 and the antimalaric drug amodiaquine ${ }^{21,22,41}$ that cause RNA Pol I stalling by intercalating with rDNA, without causing DNA damage effects. Hernandonine, another natural small molecule with anticancer activity, has also been shown to destabilize RPA194 in a proteasome-dependent manner and to inhibit nascent rRNA synthesis, however, it shows DNA damage effects ${ }^{42}$. Although sempervirine has been shown to bind DNA and RNA in vitro, we found that in vivo it preferentially bound nucleolar RNA, as revealed by in vivo labeling experiments and by RNAse A digestion. The increase of fluorescence intensity during incubation suggested that sempervirine does not freely diffuse through the cell membrane and it reaches the maximal concentration within the cell at the same time point, when the drug cytotoxicity becomes irreversible. To our knowledge, this is the first report of a molecule that is able to induce RPA194 destabilization by interacting with rRNA without inducing DNA damage. We suggest that following accumulation within the nucleolus, sempervirine hinders RNA Pol I progression and causes rRNA transcription pausing, making RPA194 sensitive to proteasome degradation. MDM2 plays an important role in this scenario since its inhibition, by ribosomal stress or its depletion, by gene silencing, are both able to decrease stability of RPA194 pointing for a protective role of MDM2 against RPA194 proteasomal degradation. It has been previously shown that MDM2 block following rRNA synthesis inhibition is responsible for the reduction of E2F1 expression and for the increase of unphosphorylated pRB levels that arrest cycle progression ${ }^{26}$. Following sempervirine-mediated MDM2 block, we found that E2F1 and pRB levels are inversely regulated both in p53-wt and p53-null TGCTs, suggesting that E2F1/pRB pathway is activated independently from $\mathrm{p} 53$, but can reinforce $\mathrm{p} 53$ pathway in $w t$ cells. In summary, we found that sempervirine, an anticancer small molecule previously described as an MDM2 inhibitor, actually is a potent inducer of nucleolar stress by destabilizing RPA194 in a proteasomedependent manner, inhibiting nascent rRNA synthesis and disrupting ribosomal content (Fig. 6c). Our results support the use of sempervirine as a RNA Pol I inhibitor, and indicate this drug as a non-genotoxic anticancer small molecule. The evidence that sempervirine can restore sensitivity to cisplatin in resistant tumor cells without inducing DNA damage, indicates that RNA Pol I targeting can parallel other therapeutic approaches to kill cancer cells.

\section{Materials and methods Cell culture}

Ten TGCT cell lines were used in this study. NT2D1, 218 A, 27X1, NCC1T, and 228 A were provided by R.S.K.
Chaganti (Memorial Sloan-Kettering Cancer Center). GCT27 cisplatin-sensitive GCT27(S) and cisplatinresistant GCT27(R) were provided by F. Viñals (Universitat de Barcelona, L'Hospitalet de Llobregat, Barcelona, Spain $)^{43} \cdot 2102 \mathrm{EP}(\mathrm{S})$ and $2102 \mathrm{EP}(\mathrm{R})$ were provided by M. Höpfner (Universitätsmedizin Berlin, Germany). Cisplatin-resistant NT2D1 sublines were generated in our laboratory over a time period of 9 months by intermittent exposure to $1 \mu \mathrm{M}$ cisplatin. After $6 \mathrm{~h}$ exposure, the cisplatin was removed from the culture medium and cells were allowed to recover 1 week until the next exposure. Myometrial cells have been described in $^{44}$. Fibroblasts were a generous gift of Dr. R. Carrozzo (Dept. of Neuroscience, Bambino Gesù Children Hospital, Rome Italy). PT-5006 ASCs were from Lonza (Basel, Switzerland).

TGCT, MiaPaCa-2, myometrial, ASCs, and fibroblast cells were cultured in DMEM high glucose (11960044 Gibco, Thermo Fisher Scientific, Waltham, Massachusetts, US) supplemented with L-glutamine (25030081 Gibco, Thermo Fisher Scientific, Waltham, Massachusetts, US), Pen/Strep (10378016 Gibco), and 10\% FBS (10270106 Gibco). Cells were grown in a $37^{\circ} \mathrm{C}$ humidified atmosphere of $5 \% \mathrm{CO}_{2}$.

\section{Chemicals and treatments}

Sempervirine is a pentacyclic anhydronium indole alkaloid isolated from the roots of the North American shrub G. sempervirens, Alton, (Loganiaceae) ${ }^{45,46}$. The more stable salt form, i.e., sempervirine chloride, belongs to a natural products collection available at the Organic Chemistry Laboratory of the Department of Chemistry and Technology of Drugs (Sapienza University of Rome, Italy ${ }^{47,48}$. The chemical identity of the molecule was assessed by re-running $1 \mathrm{H} \mathrm{NMR}$, and $13 \mathrm{C}$ NMR experiments.

Sempervirine chloride: yellow solid, m.p.: $258-60{ }^{\circ} \mathrm{C} .{ }^{1} \mathrm{H}$ $\mathrm{NMR}\left(\mathrm{CD}_{3} \mathrm{OD}, 400 \mathrm{MHz}, 25^{\circ} \mathrm{C}\right.$, TMS): $\delta(\mathrm{ppm})=8.820$ (s, $1 \mathrm{H}, \mathrm{H}-10) ; 8.528$ (d, $1 \mathrm{H}, J=7.2 \mathrm{~Hz}, \mathrm{H}-11) ; 8.331$ (d, $1 \mathrm{H}, J=6.8 \mathrm{~Hz}, \mathrm{H}-12) ; 8.284$ (s, $1 \mathrm{H}, \mathrm{H}-5) ; 8.139$ (d, $1 \mathrm{H}, J=$ $8 \mathrm{~Hz}, \mathrm{H}-4) ; 7.644-7.587$ (m, 2H, H-1 and H-2); $7.387-$ 7.348 (m, 1H, H-3); 3.160 (pseudo t, 2H, H-6, and H-6'); 3.008 (pseudo t, 2H, H-9, and $\left.\mathrm{H}-9^{\prime}\right) ; 1.991$ (m, 4H, H-7, $\mathrm{H}-7^{\prime}, \mathrm{H}-8$, and $\left.\mathrm{H}-8^{\prime}\right) .{ }^{13} \mathrm{C}$ NMR $\left(\mathrm{CD}_{3} \mathrm{OD}, 100 \mathrm{MHz}, 25^{\circ} \mathrm{C}\right.$, TMS): $\delta(\mathrm{ppm})=151.654,142.655,136.125,135.272$, $132.387,131.145,130.554,127.346,123.302,122.716$, $122.439,122.169,120.693,117.165,113.836,30.726$, 27.682, 23.066, 23.008. HRMS 273.14. ESI-MS (negative) m/z: 307.90 (calcd. for $\mathrm{C}_{19} \mathrm{H}_{17} \mathrm{Cl}$ 308.81).

Sempervirine was dissolved at a concentration of $10 \mathrm{mM}$ in DMSO (A3672 Applichem, Darmstadt, Germany) and stored at $-20^{\circ} \mathrm{C}$. Nutlin-3a (Selleck Chemicals, Verona, Italy) was dissolved at a concentration of $10 \mathrm{mM}$ in DMSO and stored at $-20^{\circ} \mathrm{C}$. Cisplatin (Cisdiammineplatinum (II) dicloride P4394, Sigma-Aldrich) 
Table 1 Cloning list.

\begin{tabular}{|c|c|}
\hline Name & Sequence \\
\hline Agel-EcoRl sh-TP53ex4 for & 5'-CCGGT-CC-GACTCCAGTGGTAATCTAC-TTCAAGAGA-GTAGATTACCACTGGAGTC-TTाTाT-G-3' \\
\hline Agel-EcoRl sh-TP53ex4 rev & 5'-AATTC-AAAAAA-GACTCCAGTGGTAATCTAC-TCTCTTGAA-GTAGATTACCACTGGAGTC-GG-A-3' \\
\hline Agel-EcoRl sh-TP53ex6 for & 5'-CCGGT-CC-ACTCCACACGCAAATTCCTT-TTCAAGAGA-AAGGAAATTGGGTGTGGAGT-TाTाT-G-3' \\
\hline Agel-EcoRl sh-TP53ex6 rev & 5'-AATTC-AAAAAA-ACTCCACACGCAAATTTCCTT-TCTCTTGAA-AAGGAAATTTGCGTGTGGAGT-GG-A-3' \\
\hline Agel-EcoRl sh-Scr for & 5'-CCGGT-CC-TAAGGTTAAGTCGCCCTCG-CTCGAG-CGAGGGCGACTTAACCTTAGG-TTाTा-G-3' \\
\hline Agel-EcoRl sh-Scr rev & 5'-AATTC-AAAAAA-TAAGGTTAAGTCGCCCTCG-CTCGAG-CGAGGGCGACTTAACCTTAGG-GG-A-3' \\
\hline
\end{tabular}

was dissolved in saline at $3.3 \mathrm{mM}$ concentration and stored at $-80{ }^{\circ} \mathrm{C}$.

\section{p53 silencing and MDM2 siRNA transfection}

Sh-scrambled (sh-scr), sh-p53ex4, and sh-p53ex6 sequences (see Table 1) were cloned into the pLKO.1 (\#8453 Addgene, Watertown, Massachusetts, US) cloning vector using AgeI and EcoRI as restriction sites, and lentiviral packaging acquisition was performed into HEK293T cells. 2101EPS cells positively infected sh-scr, sh-p53exon4, and sh-p53exon6 were selected using $(1 \mathrm{mg} / \mathrm{ml})$ puromycin (P8833 Sigma-Aldrich; Supplementary Fig. 4).

RNAi experiments were performed using Lipofectamine 3000 Transfection Reagent (L3000015 Thermo Fisher Scientific) according to manufacturer's instruction. For 2102EPS cells, we performed a double transfection using $1 \mathrm{mg}$ of iMDM2 each time, for NCCIT, we performed a single transfection using $20 \mathrm{ng}$ of iMDM2. iMDM2 and iCTR were purchased from Life Technologies (Thermo Fisher).

\section{Crystal violet assay}

Cells were seeded in a 96-well plate and the next day incubated with the appropriate drug until the end of the experimental time. The medium was discarded, cells were washed with PBS (ECB4004L Euroclone, Pero, Italy), and dried under fume hood. A total of $100 \mu \mathrm{l}$ of crystal violet solution $\left(0.2 \%\right.$ in $\left.\mathrm{H}_{2} \mathrm{O}\right)$ was added in each well and after $30 \mathrm{~min}$ the plate was washed with water. The dry plate was used to measure the OD of each well using a plate reader (OD570 $\mathrm{nm}$ ). The OD of the untreated cells is set to $100 \%$ and compared with the stimulated samples.

\section{Colony formation assay}

Single-cell suspensions were plated in six well plates (100 cells/well 2102EPS, 2102EPR, NCCIT). After 1 day, cells were treated with sempervirine or nutlin at the indicated dose. After 12-14 days, the medium was discarded, and the plates were dried under a chemical hood.
The colonies were stained with $2 \%$ methylene blue/0.1\% crystal violet solution (M9140 and C0775, SigmaAldrich).

\section{Protein extraction and western blot analysis}

Cells were extracted in $50 \mathrm{mM}$ HEPES (H3375 SigmaAldrich), 1\% Triton X-100 (T8787 Sigma-Aldrich), $100 \mathrm{mM} \quad \mathrm{NaCl} \quad$ (S7653 Sigma-Aldrich), $10 \mathrm{mM}$ $\mathrm{MgCl}_{2}$ (M8266 Sigma-Aldrich,) 10\% glycerol (G5516 Sigma-Aldrich), $0.5 \mathrm{mM}$ dithiothreitol (DTT) (D9779 Sigma-Aldrich), $\quad 10 \mathrm{mM} \quad \beta$-glycerophosphate (G9422 Sigma-Aldrich), $0.1 \mathrm{mM}$ sodium orthovanadate (450243 Sigma-Aldrich), and protease and phosphatase inhibitor cocktail (PPC1010 Sigma-Aldrich).

Antibodies used are listed in Table 2.

\section{Immunofluorescence}

Cells were fixed in 4\% PFA (157-8 Electron Microscopy Sciences, Hatfield, PA) solution in PBS, permeabilized with $0.1 \%$ Triton (X-100 Sigma-Aldrich) in PBS, and incubated with primary antibodies. Immunofluorescence for BrdU was performed fixing cells in 70\% ethanol (51976 Sigma-Aldrich) in PBS and DNA was hydrolyzed with 1.5 M HCl (H1758 Sigma-Aldrich).

Antibodies used are listed in Table 2.

Sempervirine labeling in fixed cells was performed incubating cells with a solution $5 \mu \mathrm{M}$ sempervirine in PBS. DAPI and DRAQ5 were purchased from Thermo Fisher (Monza, Italy).

RNase A (10109169001, Roche, Sigma-Aldrich) treatment was performed diluiting RNAse A in PBS at a concentration of $100 \mu \mathrm{g} / \mathrm{mg}$ for $15 \mathrm{~min}$.

\section{qRT-PCR}

RNA was extracted from cells using the Eurogold TriFast reagent according to manufacturer's instructions (EMR507100 Euroclone) and treated with RNase-free DNase (M0303 New England Biolabs, Ipswich, Massachusetts, US). A total of $2 \mu \mathrm{g}$ of RNA was retrotranscribed with $\mathrm{M}-\mathrm{MLV}$ reverse transcriptase and random primers (BIO-65050 Bioline, Cincinnati, Ohio, US). Five percent of 
Table 2 Antibodies list and dilution.

\begin{tabular}{|c|c|c|}
\hline Antibody name & Specification & Dilution \\
\hline RPA194 & sc-48385 (Santa Cruz Technologies) & $1: 1000-1: 200$ \\
\hline P53 & sc-126 (Santa Cruz Technologies) & $1: 1000$ \\
\hline MDM2 & OP46 (Sigma-Aldrich) & $1: 500$ \\
\hline UBF-1 & sc-13125 (Santa Cruz Technologies) & $1: 1000$ \\
\hline GAPDH & Ab9485 (Abcam) & $1: 2000$ \\
\hline Tubulin & \#T4026 (Sigma-Aldrich) & $1: 2000$ \\
\hline Nucleolin & sc-8031 (Santa Cruz Technologies) & $1: 1000-1: 200$ \\
\hline Fibrillarin & sc-11336 (Santa Cruz Technologies) & $1: 1000$ \\
\hline E2F1 & sc-251 (Santa Cruz Technologies) & $1: 1000$ \\
\hline BrdU & sc-32323 (Santa Cruz Technologies) & $1: 1000$ \\
\hline PARP & sc-7150 (Santa Cruz Technologies) & $1: 1000$ \\
\hline P63 & Generous gift of Prof. A. Peschiaroli & $1: 1000$ \\
\hline P73 & Generous gift of Prof. A. Peschiaroli & $1: 1000$ \\
\hline $\mathrm{Rb}$ & Sc-50 (Santa Cruz Technologies) & $1: 1000$ \\
\hline RAD51 & sc-9349 (Santa Cruz Technologies) & $1: 1000$ \\
\hline RNA pol II & sc-899 (Santa Cruz Technologies) & $1: 1000$ \\
\hline Clathrin & Ab-2731 (Abcam) & $1: 1000$ \\
\hline$\gamma H 2 A X$ & \#9718 (Cell Signaling Technologies) & $1: 500$ \\
\hline S6 & \#2217 (Cell Signaling Technologies) & $1: 1000$ \\
\hline Phospho-P53 & \#9284 (Cell Signaling Technologies) & $1: 1000$ \\
\hline P21 & sc-6246 (Santa Cruz Technologies) & $1: 1000$ \\
\hline
\end{tabular}

the reaction was used as template or qRT-PCR analysis (SYBR Green method, BIO-92005 Bioline). Primers used are listed in Table 3.

\section{Polysomes-RNPs fractionation by sucrose gradients}

A total of $80 \%$ confluent cells were homogenized in lysis buffer $(100 \mathrm{mM} \mathrm{NaCl}, 10 \mathrm{mM} \mathrm{MgCl} 2,30 \mathrm{mM}$ Tris- $\mathrm{HCl}$ (T1503 Sigma-Aldrich) pH 7.4, $1 \mathrm{mM} \mathrm{DTT,} 30 \mathrm{U} / \mathrm{ml}$ RNasin (N2111 Promega) supplemented with $0.5 \%$ Triton $\mathrm{X}-100$, protease inhibitor, and $0.5 \mathrm{mM}$ orthovanadate. After 10 min of incubation on ice, the lysates were centrifuged for $10 \mathrm{~min}$ at $12,000 \times g$ at $4{ }^{\circ} \mathrm{C}$. A total of $2 \mathrm{mg}$ of total proteins were loaded onto a $15-50 \%$ linear sucrose (0335 VWR) gradient and sedimented by centrifugation for $120 \mathrm{~min}$ at 37,000 r.p.m. in a Beckman SW41 rotor (Fullerton, CA). The optical density at $254 \mathrm{~nm}$ was measured continuously using UVcord photometer (LKB, Stockholm, SWE). Each gradient was collected in ten fractions, proteins were TCA precipitated from each fraction, and analyzed by western blot according to Barrios et al. ${ }^{49}$.
Table 3 Primers list.

\begin{tabular}{|c|c|}
\hline Name & Sequence $5^{\prime} \rightarrow 3^{\prime}$ \\
\hline DRAM1 for & TGTCTGTGCTTCACTAATTTCCA \\
\hline DRAM1 rev & TCACAGATCGCACTCACTACG \\
\hline TIGAR for & CTCCAGTGATCTCATGAG \\
\hline TIGAR rev & CATGGCCCTCAGCTCACTTA \\
\hline P21 for & GGAGACTCTCAGGGTCGAAA \\
\hline P21 rev & GGATTAGGGCTTCCTCTTGG \\
\hline RAD51 for & ACTGCAACTCTCTGGGTTGT \\
\hline RAD51 rev & GTTGTGGGCCAAAGCTTCTा \\
\hline GADD45 for & CCATGCAGGGAAGGAAAACTATG \\
\hline GADD45 rev & CCCAAACTATGGCTGCACACT \\
\hline BAX for & CCCGAGAGGTCTIITCCGAG \\
\hline BAX rev & CCGCCCATGATGGTTCTGAT \\
\hline RPA194 for & CTTCATTCTTCCACAGGGCA \\
\hline RPA194 rev & CCGAAAGGAACACAACAGCA \\
\hline UBF for & CACCCTGAGATGAGCAACCT \\
\hline UBF rev & GCCGCACTTTGAGATACACC \\
\hline TTF1 for & GCACAATCAAGCGGATGTACC \\
\hline TTF1 rev & CTTGTCTGCACTCTCAATGC \\
\hline HPRT for & TGCTGGATTACATCAAAGCACTG \\
\hline HPRT rev & TCCACCAATTACTITTATGTCCCCT \\
\hline 5'ETS_1 for & ATGGACGAGAATCACGAGCG \\
\hline 5'ETS_1 rev & CAGCCACGAACCCGACAC \\
\hline 5'ETS_2 for & GCCGCGCTCTACCTTACCTACC \\
\hline 5'ETS_2 rev & CAGACATGCATGGCTTAATCTT \\
\hline 3'ETS for & AGTCGTAACAAGGTTTCCGTAGG \\
\hline 3'ETS rev & CCTCCGGGCTCCGTTAAT \\
\hline $18 \mathrm{~S}$ for & CGCCGCTAGAGGTGAAATTCT \\
\hline $18 \mathrm{~S} \mathrm{rev}$ & CGAACCTCCGACTTTCGTTCT \\
\hline RPB1 for & TTGTAGTGAGGTTTGCGCCT \\
\hline RPB1 rev & GTCTCTGGGTATTTGATGCCA \\
\hline
\end{tabular}

\section{FACS analysis}

Eighty percent confluent cells were washed twice in PBS, collected, fixed with 70\% ethanol, and stained with propidium iodide (P4864 Sigma-Aldrich). Cell cycle analysis was carried out using flow cytometry (FACSCalibur, BD Biosciences) according to manufacturer's instructions.

\section{Statistical analysis}

All analyses were performed with Prism 7 software. All the variables have been synthesized as mean and standard deviation or mean and standard error of mean, and tests 
were considered significant for relative values $p<0.05$. All experiments were performed on at least three biological replicates.

\section{Acknowledgements}

We are grateful to R.S.K. Chaganti (Memorial Sloan-Kettering Cancer Center, New York, USA), F. Viñals (Universitat de Barcelona, L'Hospitalet de Llobregat, Barcelona, Spain), M. Höpfner (Universitätsmedizin Berlin, Germany) for TGCT cell lines; Prof. A. Peschiaroli (University of Rome Tor Vergata, Rome, Italy) for sharing mouse anti-p63 and anti-p73 antibodies. We thank Dr. R. Carrozzo (Department of Neuroscience, Bambino Gesù Children hospital, Rome, Italy). S. D. was supported by PRIN grant \#2017ATZ2YK_002; M.B. was supported by PRIN grant \#2010M4NEFY_004, and FFABR 2017; E.A.J. was supported by the PRIN grant \#2017S9KTNE_002.

\section{Author details}

'Department of Biomedicine and Prevention, University of Rome Tor Vergata, Rome, Italy. ${ }^{2}$ Department of Biotechnology, Chemistry and Pharmacy, University of Siena, Siena, Italy. ${ }^{3}$ Center for Life Nano Science@Sapienza, Istituto Italiano di Tecnologia, Rome, Italy. ${ }^{4}$ Department of Chemistry and Drug Technology, University of Rome La Sapienza, Rome, Italy. Institute of Cell Biology and Neurobiology, National Research Council of Italy (CNR), Rome, Italy. ${ }^{6}$ Department of Systems Medicine, University of Rome Tor Vergata, Rome, Italy

\section{Conflict of interest}

The authors declare that they have no conflict of interest.

\section{Publisher's note}

Springer Nature remains neutral with regard to jurisdictional claims in published maps and institutional affiliations.

The online version of this article (https://doi.org/10.1038/s41420-020-00345-4) contains supplementary material, which is available to authorized users.

Received: 19 August 2020 Accepted: 5 October 2020

Published online: 28 October 2020

\section{References}

1. Beljanski, M. \& Beljanski, M. S. Three alkaloids as selective destroyers of cancer cells in mice. Synergy with classic anticancer drugs. Oncology 43, 198-203 (1986).

2. Beljanski, M. \& Beljanski, M. S. Selective inhibition of in vitro synthesis of cancer DNA by alkaloids of beta-carboline class. Exp. Cell Biol. 50, 79-87 (1982).

3. Sasiela, C. A. et al. Identification of inhibitors for MDM2 ubiquitin ligase activity from natural product extracts by a novel high-throughput electrochemiluminescent screen. J. Biomol. Screen. 13, 229-237 (2008).

4. Hafner, A., Bulyk, M. L., Jambhekar, A. \& Lahav, G. The multiple mechanisms that regulate p53 activity and cell fate. Nat. Rev. Mol. Cell Biol. 20, 199-210 (2019).

5. Barak, Y., Gottlieb, E., Juven-Gershon, T. \& Oren, M. Regulation of mdm2 expression by p53: alternative promoters produce transcripts with nonidentical translation potential. Genes Dev. 8, 1739-1749 (1994).

6. Oliner, J. D., Saiki, A. Y. \& Caenepeel, S. The role of MDM2 amplification and overexpression in tumorigenesis. Cold Spring Harb. Perspect. Med. 6, a026336 (2016).

7. Wade, M. \& Wahl, G. M. Targeting Mdm2 and Mdmx in cancer therapy: better living through medicinal chemistry? Mol. Cancer Res. 7, 1-11 (2009).

8. Feldman, D. R., Bosl, G. J., Sheinfeld, J. \& Motzer, R. J. Medical treatment of advanced testicular cancer. JAMA 299, 672-684 (2008).

9. Feldman, D. R. et al. Presence of somatic mutations within PIK3CA, AKT, RAS, and FGFR3 but not BRAF in cisplatin-resistant germ cell tumors. Clinical cancer research: an official journal of the American Association for. Cancer Res. 20, 3712-3720 (2014)
10. Honecker, F. et al. Microsatellite instability, mismatch repair deficiency, and BRAF mutation in treatment-resistant germ cell tumors. J. Clin. Oncol. 27, 2129-2136 (2009)

11. Cavallo, F. et al. Reduced proficiency in homologous recombination underlies the high sensitivity of embryonal carcinoma testicular germ cell tumors to Cisplatin and poly (adp-ribose) polymerase inhibition. PloS ONE 7, e51563 (2012).

12. Kemp, C. J., Sun, S. \& Gurley, K. E. p53 induction and apoptosis in response to radio- and chemotherapy in vivo is tumor-type-dependent. Cancer Res. 61, 327-332 (2001).

13. Vassilev, L. T. et al. In vivo activation of the p53 pathway by small-molecule antagonists of MDM2. Science 303, 844-848 (2004).

14. Li, B., Cheng, Q., Li, Z. \& Chen, J. p53 inactivation by MDM2 and MDMX negative feedback loops in testicular germ cell tumors. Cell Cycle 9, 1411-1420 (2010).

15. Deben, $C$. et al. The MDM2-inhibitor Nutlin-3 synergizes with cisplatin to induce p53 dependent tumor cell apoptosis in non-small cell lung cancer. Oncotarget 6, 22666-22679 (2015).

16. Ohnstad, H. O. et al. MDM2 antagonist Nutlin-3a potentiates antitumour activity of cytotoxic drugs in sarcoma cell lines. BMC Cancer 11, 211-211 (2011).

17. Phan, J. et al. Structure-based design of high affinity peptides inhibiting the interaction of p53 with MDM2 and MDMX. The. J. Biol. Chem. 285, 2174-2183 (2010).

18. Andrews, P. W., Goodfellow, P. N., Shevinsky, L. H., Bronson, D. L. \& Knowles, B. B. Cell-surface antigens of a clonal human embryonal carcinoma cell line: morphological and antigenic differentiation in culture. Int. J. Cancer 29, 523-531 (1982).

19. Oechsle, K. et al. Preclinical and clinical activity of sunitinib in patients with cisplatin-refractory or multiply relapsed germ cell tumors: a Canadian Urologic Oncology Group/German Testicular Cancer Study Group cooperative study. Annals of oncology: official journal of the European Society for. Med. Oncol. 22 2654-2660 (2011)

20. Houldsworth, J. et al. Human male germ cell tumor resistance to cisplatin is linked to TP53 gene mutation. Oncogene 16, 2345-2349 (1998).

21. Espinoza, J. A. et al. The antimalarial drug amodiaquine stabilizes p53 through ribosome biogenesis stress, independently of its autophagy-inhibitory activity. Cell Death Differ. 27, 773-789 (2020).

22. Peltonen, $\mathrm{K}$. et al. A targeting modality for destruction of RNA polymerase that possesses anticancer activity. Cancer Cell 25, 77-90 (2014).

23. Burns, V. W. Studies on the fluorophore sempervirene and its complexes with DNA. Biophys. J. 14, 189-199 (1974).

24. Lohrum, M. A., Ludwig, R. L., Kubbutat, M. H., Hanlon, M. \& Vousden, K. H. Regulation of HDM2 activity by the ribosomal protein L11. Cancer Cell 3, 577-587 (2003).

25. Russo, A. \& Russo, G. Ribosomal proteins control or bypass p53 during nucleolar stress. Int. J. Mol. Sci. 18, 140 (2017).

26. Donati, G. et al. Selective inhibition of rRNA transcription downregulates E2F-1: a new p53-independent mechanism linking cell growth to cell proliferation. J. Cell Sci. 124, 3017-3028 (2011)

27. Yang, $Y$. et al. Small molecule inhibitors of HDM2 ubiquitin ligase activity stabilize and activate p53 in cells. Cancer Cell 7, 547-559 (2005).

28. Zeng, $X$. et al. MDM2 suppresses p73 function without promoting p73 degradation. Mol. Cell. Biol. 19, 3257-3266 (1999).

29. Kadakia, M., Slader, C. \& Berberich, S. J. Regulation of p63 function by Mdm2 and MdmX. DNA Cell Biol. 20, 321-330 (2001).

30. Wang, $X$. et al. MDM2 and MDMX can interact differently with ARF and members of the p53 family. FEBS Lett. 490, 202-208 (2001).

31. Jin, Y., Lee, H., Zeng, S. X., Dai, M. S. \& Lu, H. MDM2 promotes p21waf1/cip1 proteasomal turnover independently of ubiquitylation. EMBO J. 22, 6365-6377 (2003).

32. Martin, $\mathrm{K}$. et al. Stimulation of E2F1/DP1 transcriptional activity by MDM2 oncoprotein. Nature 375, 691-694 (1995)

33. Zhang, Z. et al. Novel MDM2 p53-independent functions identified through RNA silencing technologies. Ann. N. Y. Acad. Sci. 1058, 205-214 (2005).

34. Zhang, Z. et al. Stabilization of E2F1 protein by MDM2 through the E2F1 ubiquitination pathway. Oncogene 24, 7238-7247 (2005).

35. Zhang, Y. \& Lu, H. Signaling to p53: ribosomal proteins find their way. Cancer Cell 16, 369-377 (2009). 
36. Donati, G., Peddigari, S., Mercer, C. A. \& Thomas, G. 5 S ribosomal RNA is an essential component of a nascent ribosomal precursor complex that regulates the Hdm2-p53 checkpoint. Cell Rep. 4, 87-98 (2013).

37. Dai, M. S. et al. Ribosomal protein L23 activates p53 by inhibiting MDM2 function in response to ribosomal perturbation but not to translation inhibition. Mol. Cell. Biol. 24, 7654-7668 (2004).

38. Dai, M. S. \& Lu, H. Inhibition of MDM2-mediated p53 ubiquitination and degradation by ribosomal protein L5. J. Biol. Chem. 279, 44475-44482 (2004).

39. Cavanaugh, A. H. et al. Activity of RNA polymerase I transcription factor UBF blocked by Rb gene product. Nature 374, 177-180 (1995).

40. Voit, R., Schafer, K. \& Grummt, I. Mechanism of repression of RNA polymerase I transcription by the retinoblastoma protein. Mol. Cell. Biol. 17, 4230-4237 (1997).

41. Drygin, D. et al. Targeting RNA polymerase I with an oral small molecule CX5461 inhibits ribosomal RNA synthesis and solid tumor growth. Cancer Res. 71 , 1418-1430 (2011).

42. Chen, Y. T., Chen, J. J. \& Wang, H. T. Targeting RNA polymerase I with hernandonine inhibits ribosomal ma synthesis and tumor cell growth. Mol. Cancer Res. 17, 2294-2305 (2019).
43. Kelland, L. R. et al. Establishment and characterization of an in vitro model of acquired resistance to cisplatin in a human testicular nonseminomatous germ cell line. Cancer Res. 52, 1710-1716 (1992).

44. Dolci, S. et al. Subcellular localization and regulation of type-1C and type-5 phosphodiesterases. Biochem. Biophys. Res. Commun. 341, 837-846 (2006)

45. Berardozzi, S. et al. Synergistic inhibition of the Hedgehog pathway by newly designed Smo and Gli antagonists bearing the isoflavone scaffold. Eur.J. Med. Chem. 156, 554-562 (2018).

46. Stevenson, A. Ea. S. L. E. Sempervirine from gelsemium root. J. Am. Pharm. Assoc. 4, 1458-1463 (1915).

47. Casciaro, B. et al. Nigritanine as a new potential antimicrobial alkaloid for the treatment of Staphylococcus aureus-induced infections. Toxins 11, 511 (2019).

48. Adewunmi, C. O., Monache, F. D. \& Marquis, F. D. Molluscicidal activities of some alkaloids. Bull. Chem. Soc. Ethiop. 3, 103-106 (1989).

49. Barrios, F. et al. Opposing effects of retinoic acid and FGF9 on Nanos2 expression and meiotic entry of mouse germ cells. Journal of cell science $\mathbf{1 2 3}$, $871-880$ (2010) 